\title{
Analysis the First Arrival of P-Wave of Ina-TEWS and CTBT Stations to Support Earthquake Early Warning
}

\author{
Hendar Gunawan ${ }^{1}$, Nanang T. Puspito ${ }^{2}$, Gunawan Ibrahim $^{2}$ and Prih. Harjadi ${ }^{1}$ \\ 1. Indonesian Meteorological, Climatological and Geophysical Agency (BMKG), Kemayoran 10720, Indonesia \\ 2. Bandung Institute of Technology, Faculty of Earth Science (FITB), Bandung 40116, Indonesia
}

\begin{abstract}
The authors make the analysis of first arrivals of the P-wave from Ina-TEWS (Indonesian tsunami early warning system) and CTBT (comprehensive nuclear-test-band treaty) stations. These are used for earthquake early warning, magnitude determination and potential earthquake hazard mitigation based on seismogram acceleration. This research is focused on the study of energy duration of high frequency, and the maximum displacement of P-waves by observing broadband seismograms. The further analysis consists of deconvolution, integration or defferentiation, recursive filtering for data restitution, and applying a Butterworth filter of second order. The Butterworth filter uses high frequency $0.075 \mathrm{~Hz}$ to cut the effect of drift, and band-pass frequency $2-4 \mathrm{~Hz}$ for use in magnitude calculation. The authors choose potentially damaging earthquakes to be greater than $M w>6.0$. Based on the trigger on the three seconds the first arrival P-wave, the dominant period $(T d)$ and amplitude displacement $(P d)$ was calculated by using data CISI (Indonesian CI Sompet) seismological station, Garut (west Java) and tested for data CTBT, LEM bang, Bandung (LEM station). This research resulted determination of the P-wave arrival time accurately using integrated skewness and kurtosis. Performance data from the CTBT stations is very high. Signal to noise ratio $>1,000$ after passing through the filter. Such riset conducted to find out a rapid magnitude estimations from predominant frequency of displacement are: $\log T d=0.2406 M-1.3665(R=0.73)$ or $M=4.156$ $\log T d+5.6797$. Relationship of $P d$, magnitude moment, $M w$ and hypocentre, $R$ are $\log P d=-4.684+0.815 M w-1.36 \log R$. For relation of $P G A$ (peak ground acceleration) and amplitude displacement are $\log P G A=1.117 \log P d+0.728(R=0.91)$. Furthermore, this formula can be used to support earthquake early warning in west of Java.
\end{abstract}

Key words: Earthquake early warning, displacement, peak ground acceleration.

\section{Introduction}

Early warning for earthquake disaster mitigation is very possible with the development of high technology seismic sensors and the frequency broadband, densely earthquake observation network in Indonesia 150 broadbands, data acquisition systems, modern computer data processing and high-capacity servers, system of satellite communications that are reliable and the system of dissemination of information on the DVB (digital video broadcasting) telecomunication support system which already operates $24 \mathrm{~h}$ a day, seven days a week. Ina-TEWS (Indonesian tsunami early warning systems) has successfully provided the information parameters of the earthquake and tsunami warning in

Corresponding author: Hendar Gunawan, Ph.D. student, research field: seismologist. hendargunawan@hotmail.com. less than $5 \mathrm{~min}$, but the earthquake early warning systems not yet developed. Success in early warning of potential mitigation of earthquake disasters have been recorded successfully include: SAS (seismic alert system) in Mexico, on September 14, 1995 Mexican earthquake, magnitude 7.1, a warning has been given within $72 \mathrm{~s}$ before strong shaking through the city of Mexico [1]. During the operation from August 1991 to May 2005, SAS has successfully detected the 1783 earthquakes with magnitudes $5.2<M<7.3$ and provide early warning 11 times and 46 times warning of the limited, one failed warning during 1993. Wu et al. [2] developed a rapid early warning for earthquake disaster mitigation potential for $T d>1 \mathrm{~s}$ or $P d>0.5$ $\mathrm{cm}$ as the limit of the commencement of an earthquake early warning that will impact damage to the affected areas. 
JMA (Japan meteorological agency) in the event of big quake Tohoku, March 15, 2011, magnitude 9.0, at local time of $02: 46: 45$, has managed to give warning automatically at $3 \mathrm{~s}$ after the earthquake occurred at local time of 02:46:48. Earthquake early warning broadcast on network TV, radio, telephone handheld (mobile), schools and factories. Another earthquake early warning systems in the world today were developed such as the IERREWS (Istanbul earthquake rapid response and early warning system) in Turkey, earthquake early warning in Romania, rapid earthquake information system in Taiwan. More over in China, Switzerland, Italy, California and the Pacific Tsunami Warning Centre, still in test trials in a real time. Since 2005, BMKG (Meteorological, Climatological and Geophysical Agency) developed seismic network in whole Indonesian region with 161 broadband sensors. The data format is velocity seismogram. But EEWS (earthquake early warning system) has not yet established. Bisides Jakarta is the capital city with high risk ground shaking. Empirical formula of predominant period $(T d)$ has relationship with magnitude not yet available. The purpose is to develop EEWS correlated to predominant period and earthquake magnitude based on analysis of P-wave arrival time from broadband seismogram. The authors use integration of skewness and kurtosis and its combinations methods for automatic determination of P-wave arrival time. Then the authors create the related model of the first $3 \mathrm{~s}$ of P-wave dominant period with $M w>6.0(T d$ vs. $M)$ and estimation $P G V$ (peak ground velocity) from Amplitudo displacement $P d$ vs. $P G V$. This research focused to study characteristic of EEW (earthquake early warning) from broadband velocity seismogram data. The motivation of this research is to find formulations dominant period of high frequency $\mathrm{P}$-wave $(T d)$ with magnitude approaches $(M T d)$ that recorded by CISI seismic stations and try to compare with LEM, Bandung station. Researchers also look for formulas relationship amplitude displacement $(P d), \quad M T d$, hypocentral distance $(R)$ and $P G A$ (peak ground acceleration) in particular earthquakes with magnitude $M w>6$, and find the limit of the threshold to provide an earthquake warning issue. Area of research is west of Java region: coordinates $104^{\circ}-109^{\circ}(\mathrm{E})$ and $5^{\circ}-9^{\circ}(\mathrm{S})$ and preliminary study for broadband data BMKG 2009-2010.

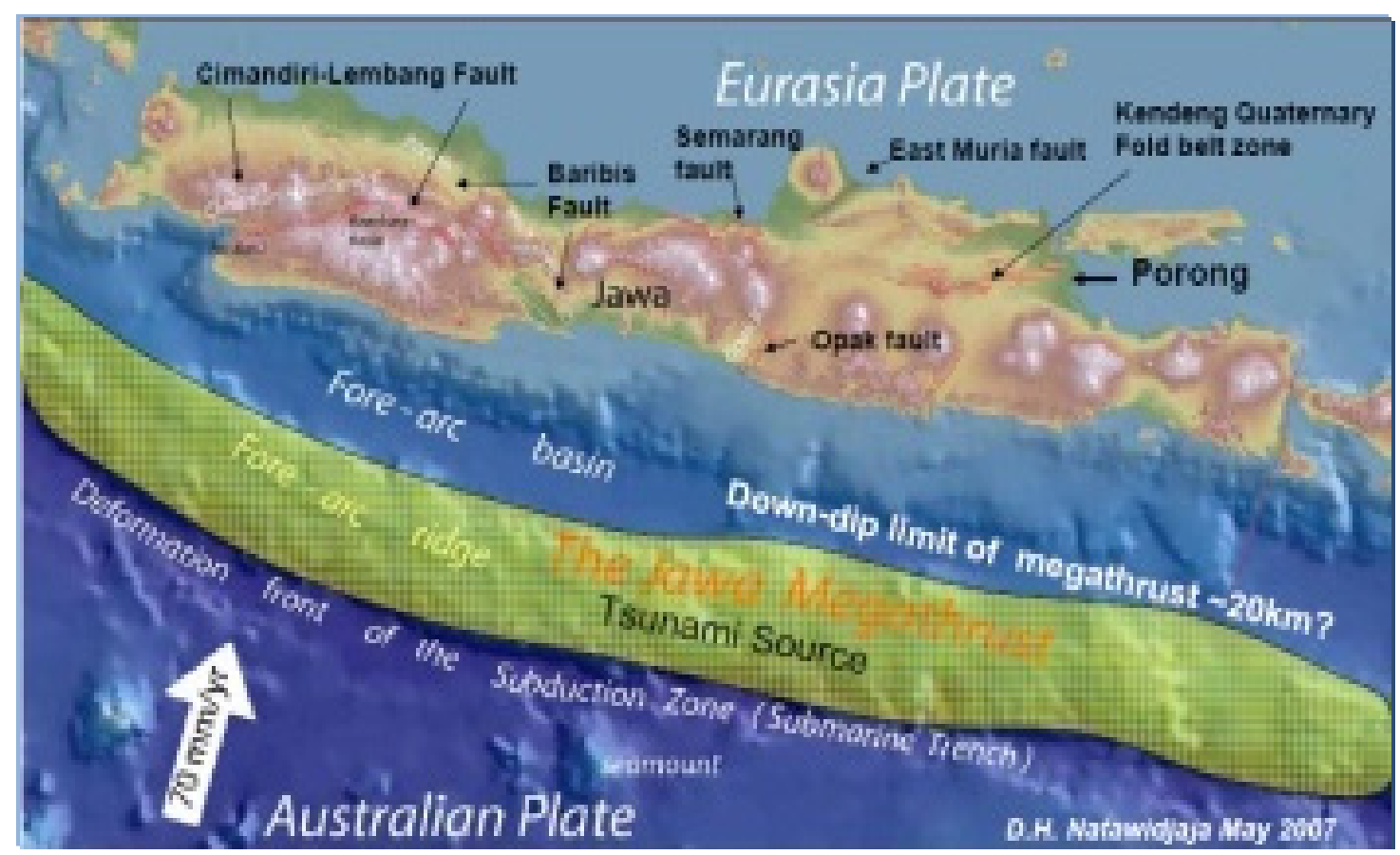

Fig. 1 Tectonic setting of Java. 


\section{Seismicity of West Java Region}

In western Java, there are tectonic earthquake source comes from mega-thrust and Beniof zone on the Indian Ocean. Australian Tectonics Plate collision with the Eurasian plate, so strong earthquake potential happened with shallow depth and potentially damage in addition to local fault on land. Australian plate moves $70 \mathrm{~mm} /$ year in the north direction. Fig. 1 showed tectonic setting of Java. High seismicity level indicated at least 28 times the incidence of strong earthquakes in western Java and was felt in Jakarta as well as such cause a tsunami.

The history of the earthquakes that occurred in Tasikmalaya 1979 (10 killed, 1,430 houses collapsed), in Majalengka 1990 (8,000 homes collapsed), in Sukabumi 2000 (35 people seriously injured, 633 houses were severely damaged), in Gununghalu 2005 (135 houses were severely damaged), in Pangandaran with tsunami in 2006 (550 dead) and in Tasikmalaya with tsunami in 2009 (117 people died, 1,254 people injured, 63,717 houses were severely damaged and 131,216 minor damages).

Fig. 2 showed the distribution of the epicenter in the western part of Java island arc based on the variation of the average depth is generally shallow earthquake, or a depth of less than $60 \mathrm{~km}$, as a result of collision activity on the system of oceanic plate subduction and active faults on land west of Java.

\section{Method}

The method used in this paper is the calculation of the duration of high frequency energy and maximum displacement of the P-wave using a digital data broadband seismograms. Input digital data broadband seismograms, in the early stages was chosen to signal $\mathrm{P}$ from the data first arrival of P-wave of the earthquake ( $t$ zero). Usually seismograph instrument equipped with alarm or SAS. Advanced analysis of digital seismograms broadband to process filter recursion (filtering, windowing, Butterworth-order 2, zero seismogram). The process of restitution by way of integration and differentiation signals generates velocity broadband seismograms to displacement or acceleration. Seismogram displacement during period of $3 \mathrm{~s}$ and then determine the first P-wave, and analyze the predominant period of $T d$. The authors conduct analysis of seismic signal P-wave phase of vertical component that have potential damage on $M w>6.0$. Fig. 3 is distribution of earthquake epicenter of Tasikmalaya earthquake and their aftershock with magnitude, $M=7.2$. Seismic network in the western part of Java is supported by 15 broadband stations and six stations of which are geographically situated along the southern coastline of western Java more or less parallel to the subduction zone.

Damaging earthquake source is located in the south western part of Java about $200 \mathrm{~km}$ from the coastline, so there are about $300 \mathrm{~km}$ from the city of Jakarta.

Scope of the area of this research is to find out formulation of EEW parameter such as $T d, P d$ from $3 \mathrm{~s}$ P-wave arrival and estimation of $M$ and $P G A$ area of research are west of Java region: coordinates $104^{\circ}-109^{\circ}(\mathrm{E})$ and $5^{\circ}-9^{\circ}(\mathrm{S})$, broadband seismogram data BMKG 2009-2010.

\section{Data}

Data used in this study include are 68 earthquakes data after the Tasikmalaya earthquake on September 2,

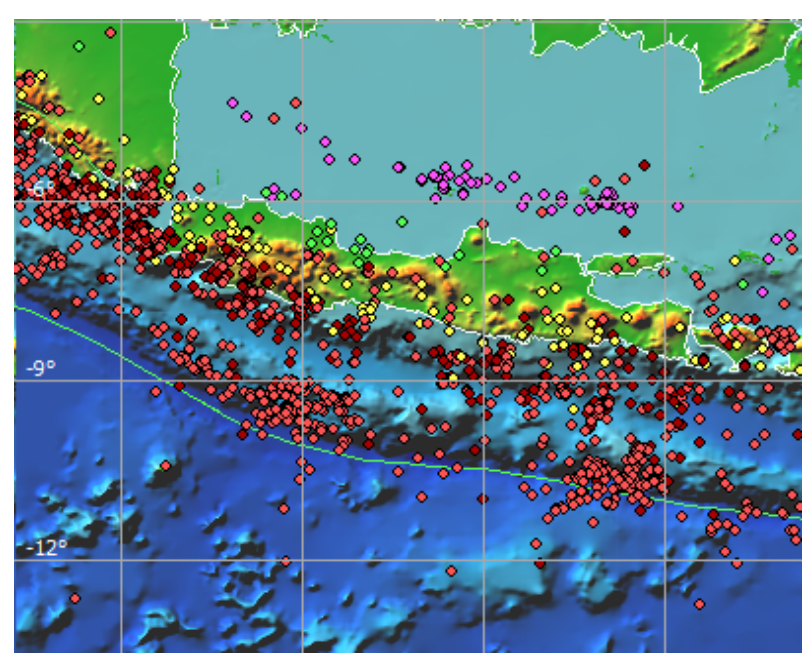

Fig. 2 Seismicity map of Java (1900-2010). 


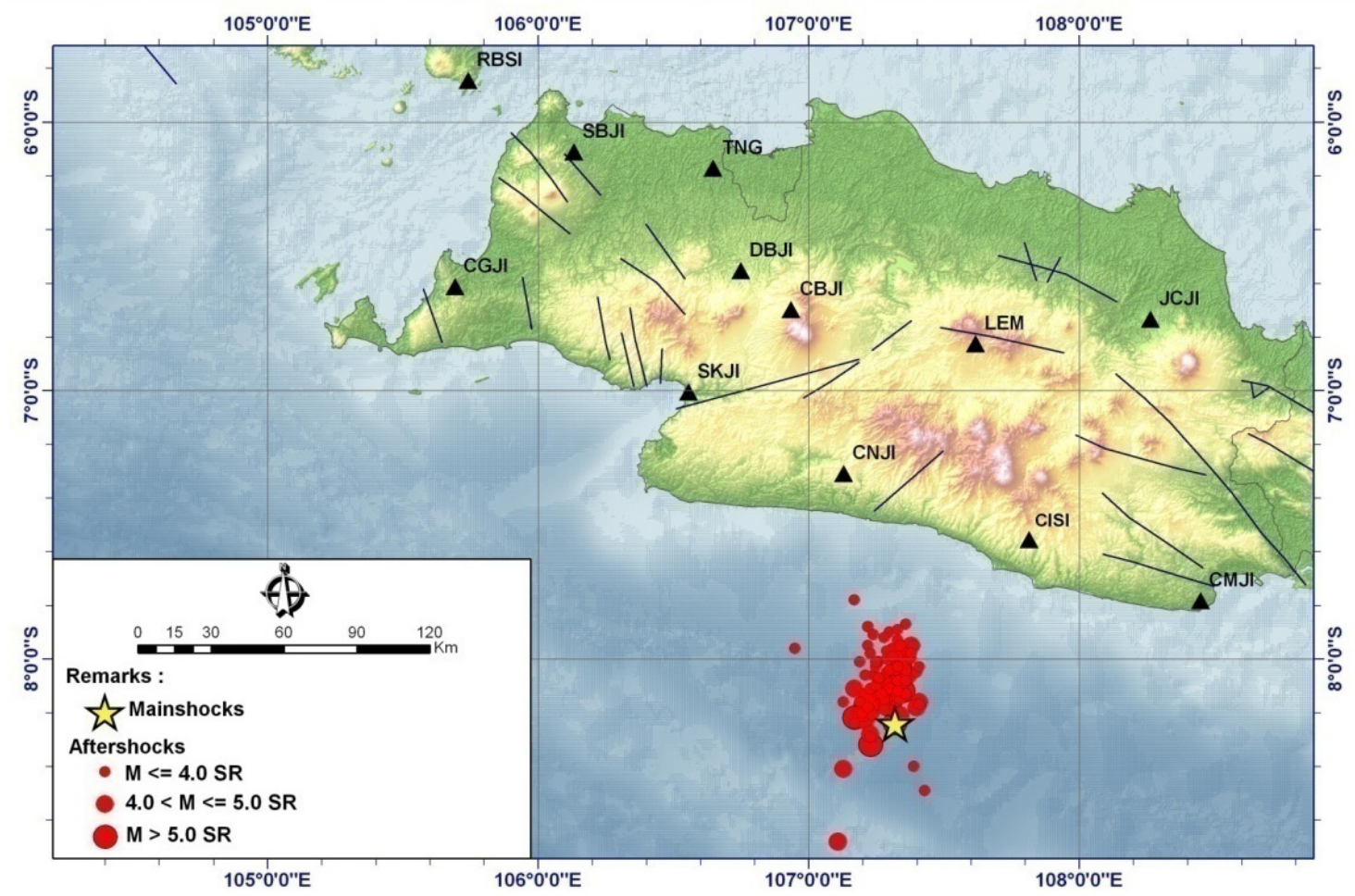

Fig. 3 Distributions of 2009 Java Tasikmalaya earthquake (M7.2) and aftershocks.

2009, at 07:55:00.8 GMT (Greenwich mean time), Magnitude $7.2 \mathrm{RS}$ (Richter scale), depth is $10 \mathrm{~km}$, at 8.24S, 107.32E and their after-shock. The authors also collected dominant period $(T d)$ of 62 earthquake from LEM (CTBT's) station, Bandung, West java, closed to mega-thrust in South of Java. In the data processing there is the contribution of interference (noise) caused by long wave interference and local disturbance broadband velocity seismogram. By using Butterworth band pass filter 2 nd order, the frequency of $2-4 \mathrm{~Hz}$ then be integrated to obtain displacement seismograms for further processing (Fig. 4).

\section{Determination of P-Wave Arrival Time}

Determination of seismic P-wave arrival time quickly, accurately and with high effectiveness is very important for monitoring seismic activity in real time, determination of epicenter, the accuracy of the determination of the dominant period of earthquake and EEW information. P-wave arrival time can be determined manually, directly from seismograms without going through the filtering process first. This work is usually done by an experienced observer so as to obtain good results but the results are less rapid, ineffective and highly dependent on the subjectivity of observer. The number of seismic sensors that much, can not be done by the observer that requires the expert to seek alternatives to the determination of earthquake automatically. Determination of arrival time there are two steps:

(1) Determination of arrival time must be precise, accurate and reliable for every arrival of seismic waves, not the interference (noise);

(2) Identification of arrival time to describe the character of the wave polarization, amplitude, according to the direction of arrival wave.

Automatic determination occasionally occur signal interference caused by the earthquake due to frequent superposition with other energy from seismic sources teleseismic or local interference. Even for a local earthquake, the duration of an unfinished wave has come another P-wave phase. To obtain P-wave arrival 


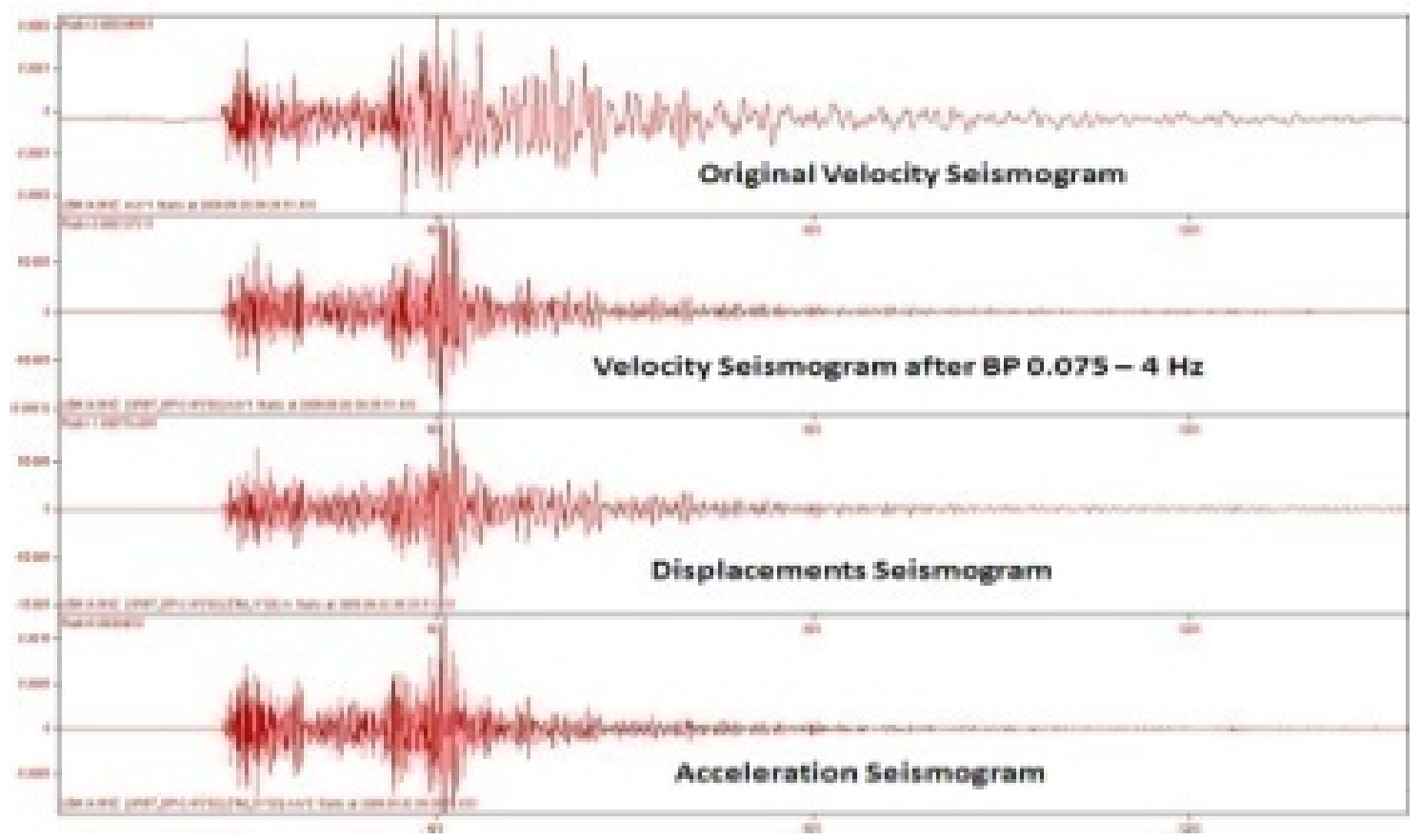

Fig. 4 CTBT, LEM, Bandung seismogram analysis of 2009 Tasikmalaya Java (M7.2).

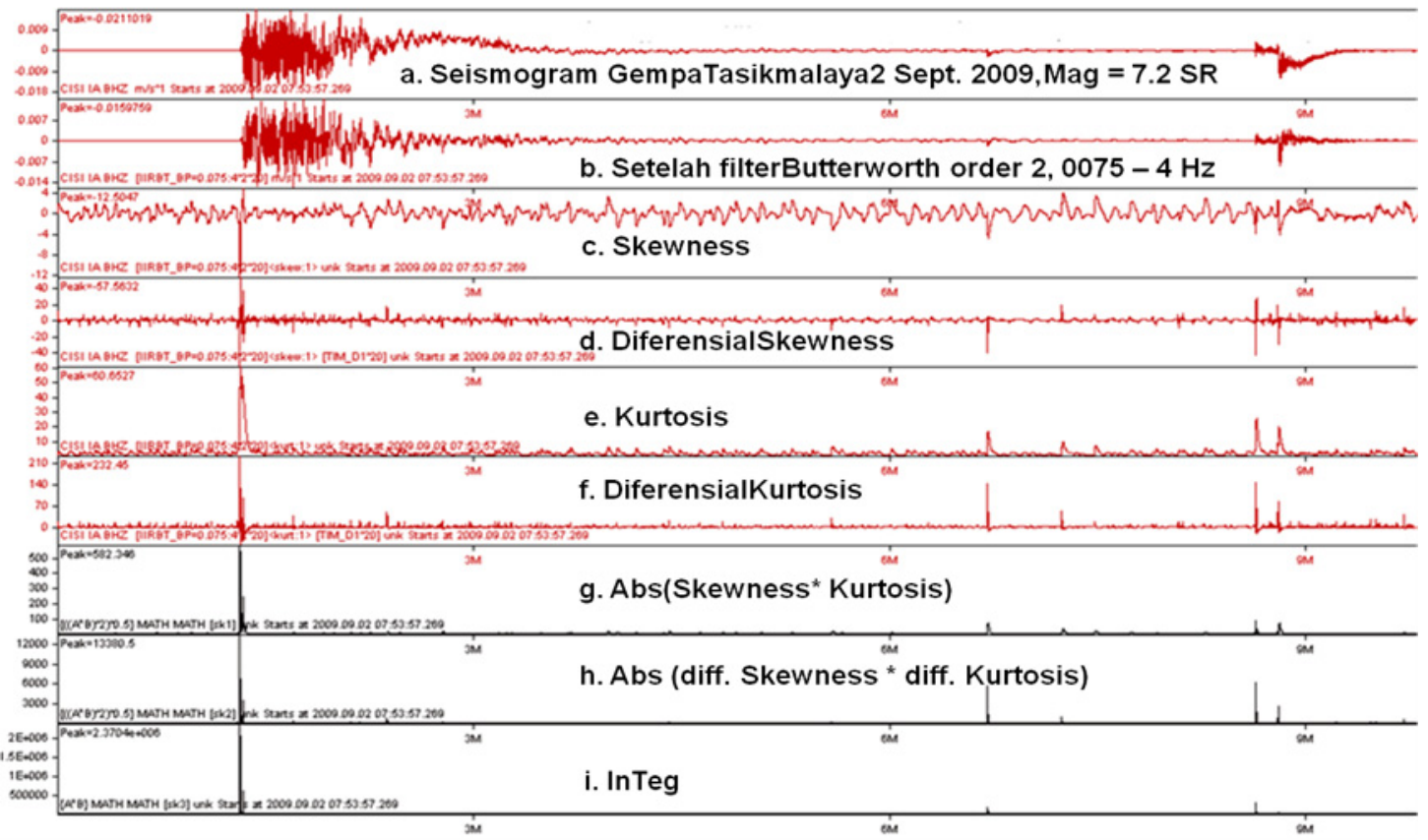

Fig. 5 Determination P-wave arrival using InTeg method.

time can be done with the algorithm in frequency domain and time domain or a combination thereof. Time domain approach is commonly used, namely the average ratio $S T A$ (short-time average) divided by the average length of data LTA (long-time average),
$S T A / L T A$ and multi-window algorithm [3], with the basic idea if the $S T A / L T A$ exceeds a specified threshold will be selected $\mathrm{P}$-wave arrival time.

A technique for automatic detection of onset time [4]. polarization analysis [5], kurtosis methodology in time 


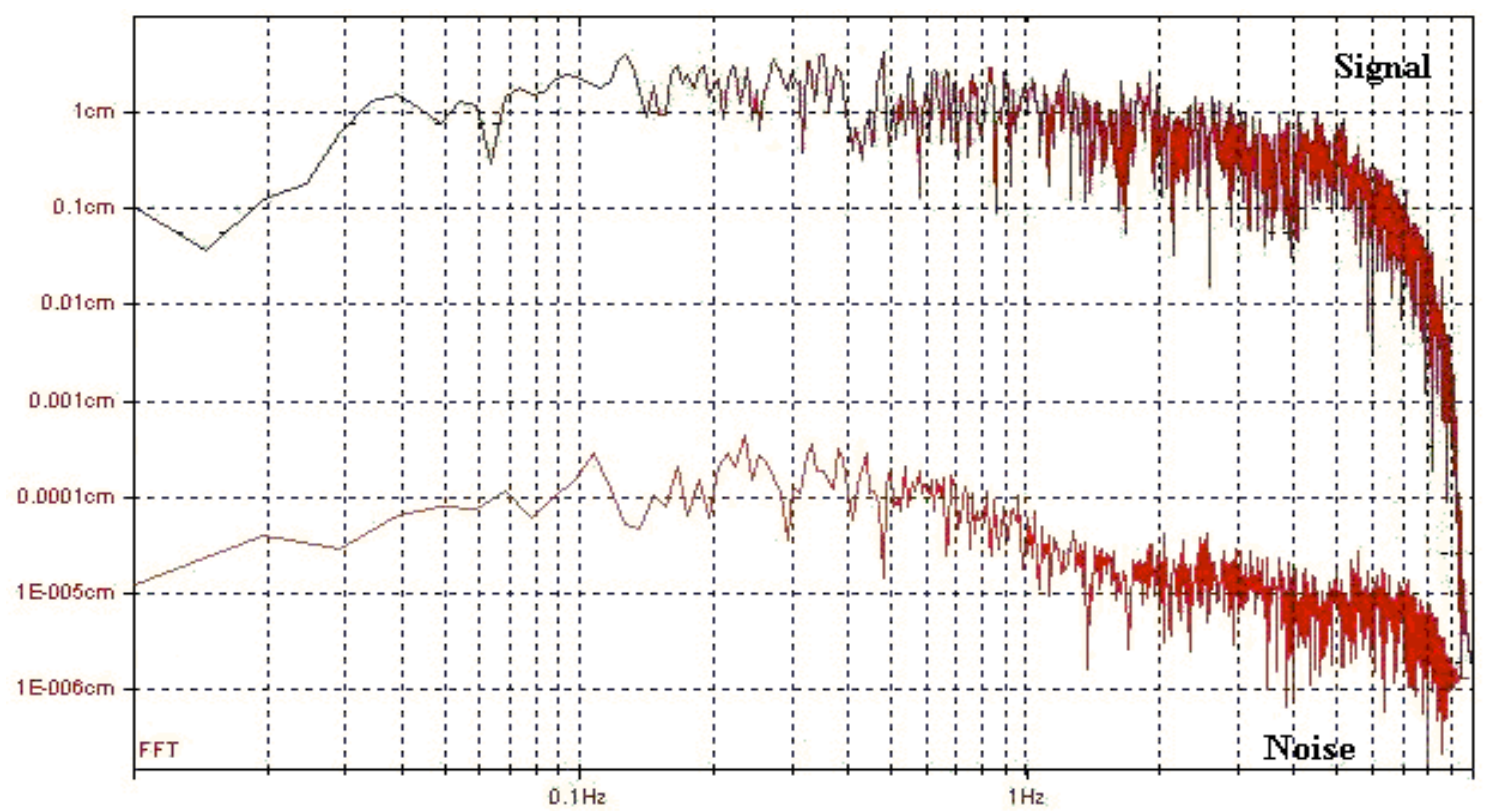

Fig. 6 Spectral signal and noise CISI station on Tasik EQ's on September 2, 2009.

domain, combined with the Haar wavelet [6], and analysis with neural network artificial [7]. In this study, the identification of P-wave arrival time is used algorithms kurtosis and skewness and its combination with differential skewness and kurtosis (InTeg).

Determination of P-wave arrival time using InTeg methode showed in Fig. 5. Performance of the data depends on signal to noise ratio. Fig. 6 shows the spectral amplitude of signal and noise at CISI station on Tasikmalaya earthquake on September 2, 2009. Signal to noise ratio greather than $10^{3}$ or more than 10 .

The performance data are good, signal very clear and noise very small. The authors have been already processed the 68 earthquakes at the CISI station. Residue data tends to negative with an average value of $-0.052 \mathrm{~s}$, the standard deviation of $0.545 \mathrm{~s}$, standard error is $0.06 \mathrm{~s}$. Residues dominant area of approximately $0.25 \mathrm{~s}$, and $1.25 \mathrm{~s}$ in the range of residues.

The results show that the difference methods of InTeg with $S T A / L T A$ ratio is about $-0.063 \mathrm{~s}$ on average error, the standard deviation of $0.393 \mathrm{~s}$ and standard error equal $0.048 \mathrm{~s}$. Residual associated with errors in the epicenter determination method of STA/LTA -0.051 $\mathrm{s}$ on average error, standard deviation $0.545 \mathrm{~s}$ and standard deviation errors $0.06 \mathrm{~s}$. If the time residual of earthquake epicenter is removed by InTeg methods has been found error average of $0.011 \mathrm{~s}$, the standard deviation of $0.626 \mathrm{~s}, 0.076 \mathrm{~s}$ with a standard error. From the analysis, InTeg method has high accuracy, reliable and can be used in determining the parameters of EEW. Error determination of earthquake arrival time by InTeg method is $0.01 \mathrm{~s}$ to $0.1 \mathrm{~s}$, or an average of $0.011 \mathrm{~s}$, the standard deviation of $0.62 \mathrm{~s}$ and standard error $0.075 \mathrm{~s}$

InTeg method is more accurate and reliable for the determination of the $\mathrm{P}$-wave arrival time so that supports the calculation of parameters of the dominant period in EEW which has a maximum standard error $0.01 \mathrm{~s}$

\section{Results and Discussions}

\subsection{Lead Time}

Time effective early warning earthquake $\Delta t w$ defined as the time interval between the detection of early phases of the P-wave at stations CISI with the arrival of destructive waves, at a specific target location (lead time) the city of Jakarta or Bandung can be expressed as follows: 


$$
\Delta t w=\frac{\sqrt{x b^{2}+h^{2}}}{\beta}-\frac{\sqrt{x a^{2}+h^{2}}}{\alpha}-\Delta t p
$$

where,

$x a=$ distance of the epicenter with an earthquake sensor;

$x b=$ distance of the target with the source of early warning;

$\alpha, \beta=\mathrm{P}$-wave velocity and $\mathrm{S}$-wave velocity;

$h=$ depth of source;

$\Delta t p=$ time required for data processing.

If the P-wave velocity is on average $6.8 \mathrm{~km} / \mathrm{s}$, S-wave velocity is $3.4 \mathrm{~km} / \mathrm{s}$ and the required processing time is less than $5 \mathrm{~s}$, then the potential for early warning of Jakarta from the earthquake source shallow megathrust can be given within a period of approximately $118 \mathrm{~s}$ (Fig. 7).

\subsection{Calculation of Maximum Displacement Frequency Td}

The process of recursive Butterworth filter high pass filter with cut off frequency $0.075 \mathrm{~Hz}$ applied to the broadband seismograms of digital data to eliminate low frequency drift effects during the initial process of restitution or integration and differentiation (Fig. 8). Noise in the data filtered with a bandpass filter frequency of 2-4 Hz. Based on data from velocity of digital seismograms that have been processed into the displacement.

Application data in 68 earthquakes recorded by seismic stations (CISI) Cisompet, Garut, West Java has been processed for $M=2.5 \mathrm{RS}$ earthquake with a magnitude up to $M=7.2 \mathrm{RS}$ sourced from intra plate and megathrust zone at west of Java.

$T d$ parameterization also observed for 62 earthquake data recorded by LEM, CTBT station, Bandung-west Java.

\subsection{The Mathematical Model Td and M}

The main element in early warning mitigation potential earthquake can be expressed in the calculation of dominant period of displacement seismogram and $T d$ and forecasts magnitude quickly and can be trusted to determine the size of the earthquake, when creeping of fault earthquake (rupture) stopped during the period of motion of an earthquake occurs.

The observations of the dominant period of displacement $T d$, obtained from the P-wave maximum amplitude on the seismogram displacement. Mathematical model of $M$ and $T d$ is a logarithmic relationship with the least square fit (Fig. 9).

Relations predominant period $T d$ and $M$ for 68 earthquakes recorded by station Cisompet, Garut, west Java, which comes from Megathrust earthquake in the south of Java:

$$
\log T d=0.240 M-1.367, R=0.72
$$

or

$$
M=4.156+5.679 \log T d
$$

where, $T d=$ predominant period of displacement, $M=$ MTd (moment magnitude) or $M w$.

Determination of the dominant period displacement $T d$ for 68 earthquake records obtained by the results of $0.145 \mathrm{~s}$ time period up to $2.64 \mathrm{~s}$ with a standard deviation of 0.1-0.23 s. Td associated with smaller magnitude $4 \mathrm{RS}$ up to a larger $7 \mathrm{RS}$ (Table 1). Concentration distribution data are still around magnitude 4 RS up to $5 \mathrm{RS}$, so that it should be added to data of the earthquakes with magnitude $M>5 \mathrm{RS}$.

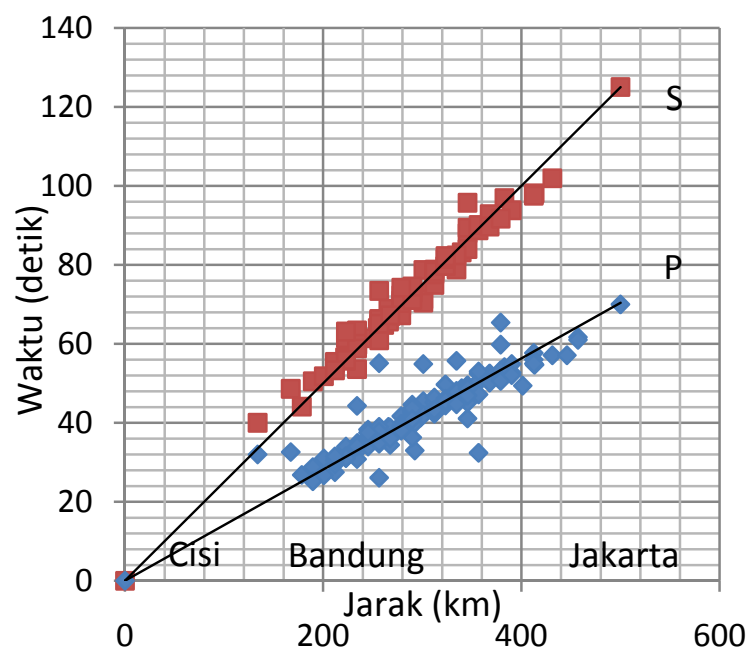

Fig. 7 Potential EEW for Bandung and Jakarta closed to mega-thrust in South Java. 


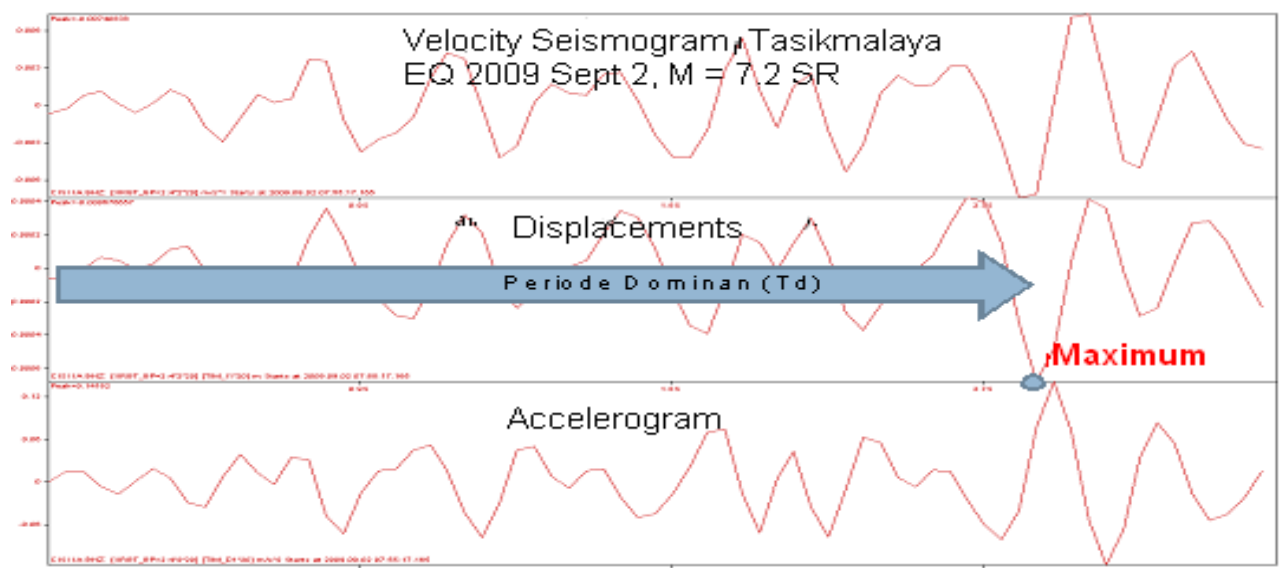

Fig. 8 Restitution of velocity seismograms to the velocity and displacement of earthquake seismograms Tasikmalaya, 2009 which is recorded by the station (CISI) Cisompet, Garut, west Java.

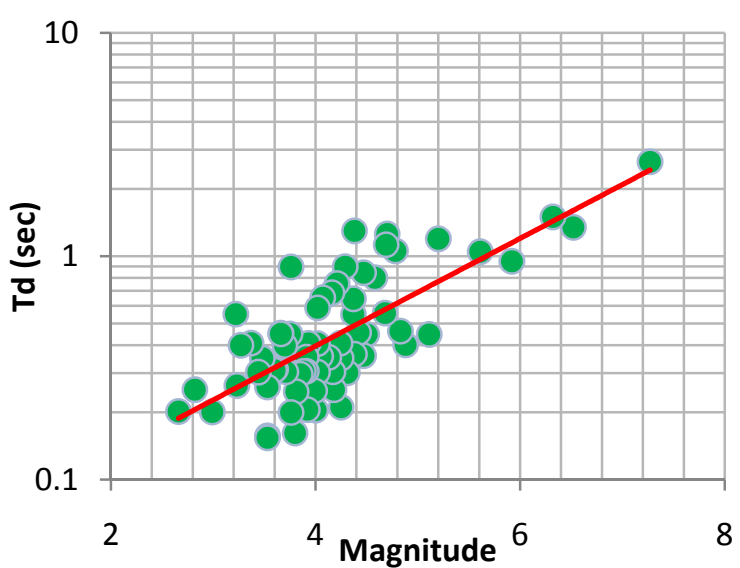

Fig. 9 Relations $T d$ with magnitude.

Table 1 Relationship predominant period $(T d)$ with magnitude $(M)$.

\begin{tabular}{lll}
\hline No. & Magnitude $(M)$ & Dominant period $(T d)$ \\
\hline 1 & $4.0>M$ & $0.4>T d \pm 0.1$ \\
2 & $5.0>M>4.1$ & $0.7>T d>0.41 \pm 0.1$ \\
3 & $6.0>M>5.1$ & $1.2>T d>0.71 \pm 0.2$ \\
4 & $7.0>M>6.1$ & $2.1>T d>1.21 \pm 0.1$ \\
5 & $M>7.1$ & $T d>2.2$ \\
\hline
\end{tabular}

In Table $1, M>6.0$ selected for strong enough that can be felt by the entire region west Java and potentially damage. Furthermore, the dominant period of seismic analysis results and then chosen to $T d>$ $1.2 \mathrm{~s}$.

Calculation of magnitude associated with the dominant period of seismograms displacement aimed at getting magnitude approach. Eqs. (2) and (3) have a characteristic slope of 4.156292 , time of +5.679699 intercept and correlation factor of 0.7273 . This value is relatively similar when compared with $\mathrm{Wu}$ et al. [8]. Furthermore, by way of linear regression was also calculated $T d$ magnitude relationship with the magnitude calculation from BMKG results. $T d$ magnitude parameter Eq. (4) is used as a magnitude estimation.

MTd value is generally higher than the local magnitude $\mathrm{BMKG}$, because the used seismogram is displacement. Magnitude $T d$ in a variety of writings called the magnitude of the moment approach $(M w)$.

Relationship between magnitude and local magnitude $M$ is show in Fig. 10 and formulation result in Eq. (4):

$$
M T d=1.001 M+0.005, R=0.727
$$

Relation of amplitude displacement $P d$, Magnitude $M w$ and hypocenter distance $R$ calculated by using Gauss-Jordan methods for linier fit program. Formulation of $P d, R$ and magnitude for $M=3,4,5,6,7$.

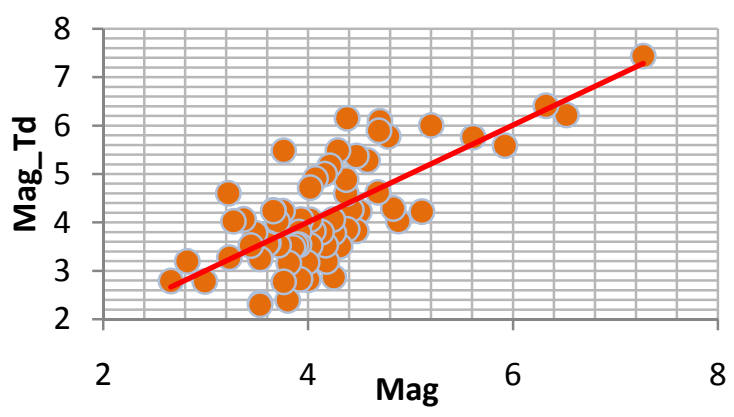

Fig. 10 Relationship MTd with magnitude. 


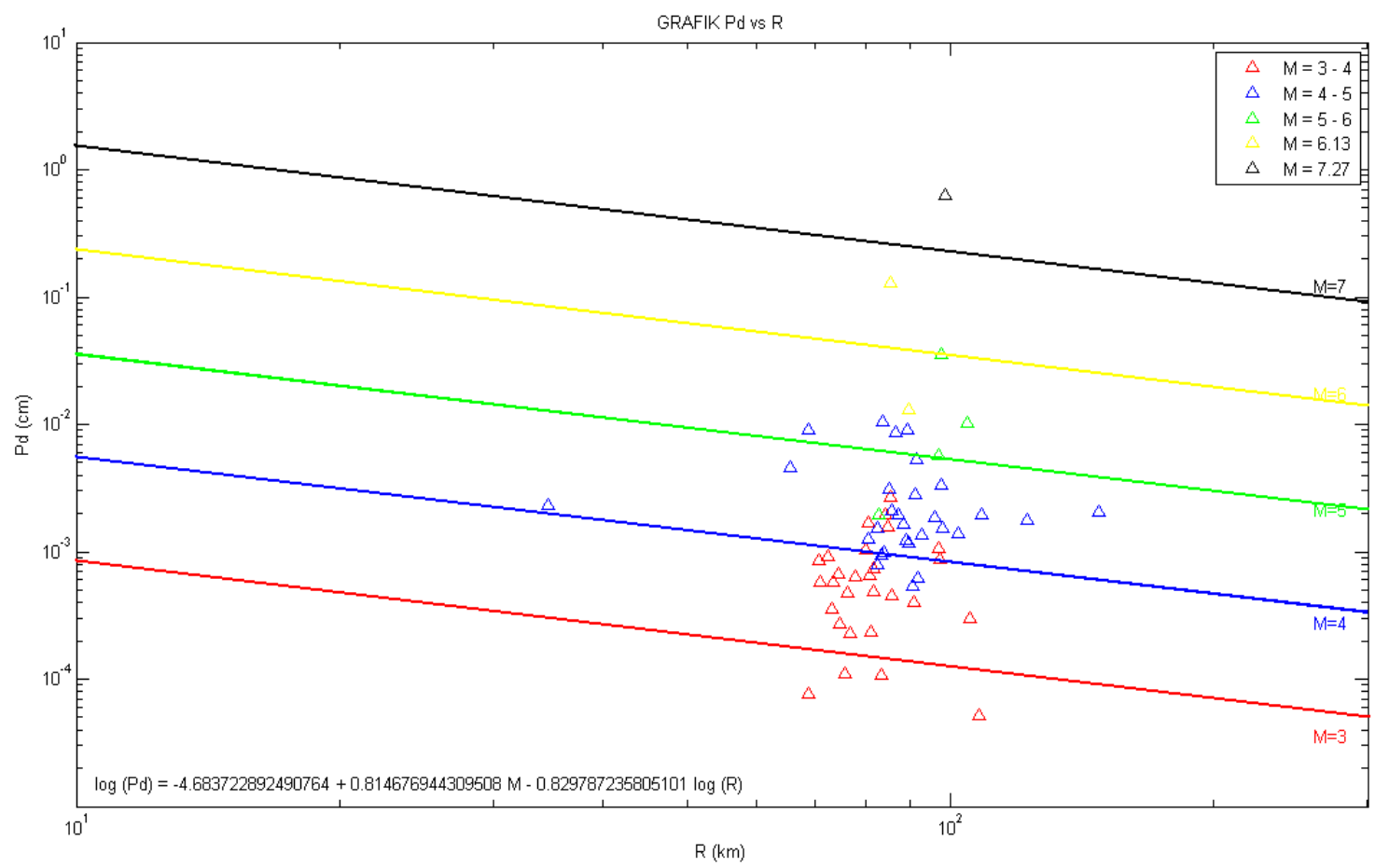

Fig. 11 Correlation among $P d$, hypocenter distance and $M=3,4,5,6,7$.

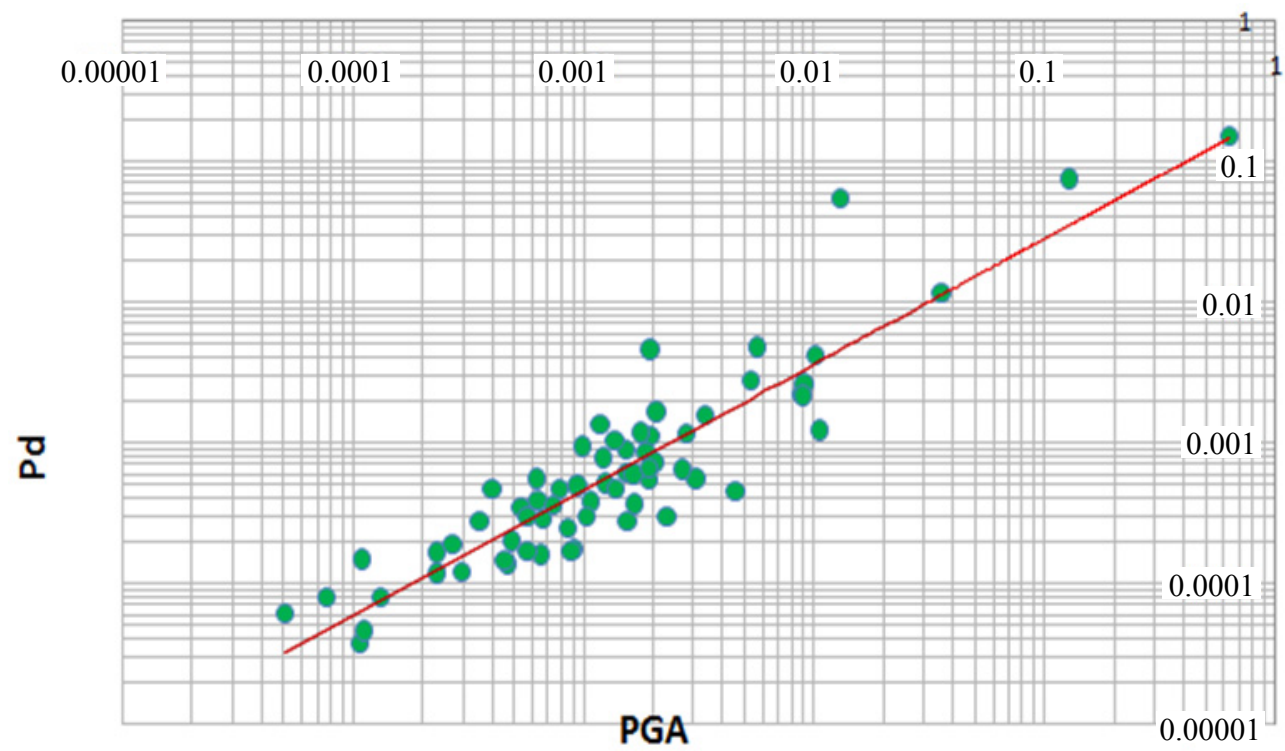

Fig. 12 Correlation ratio $P d$ and $P G A$.

Table 2 Relationship amplitude displacement $P d$ with PGA.

\begin{tabular}{lll}
\hline No. & $P G A(\%, \mathrm{~g})$ & Amplitude displacement $P d(\mathrm{~cm})$ \\
\hline 1 & $5>P G A$ & $0.1>P d \pm 0.1$ \\
2 & $10>P G A>0.05$ & $0.25>P d>0.1 \pm 0.1$ \\
3 & $25>P G A>0.1$ & $0.5>P d>0.25 \pm 0.2$ \\
4 & $50>P G A>0.25$ & $1.0>P d>0.5 \pm 0.1$ \\
5 & $P G A>50$ & $P d>1.0$ \\
\hline
\end{tabular}

$\log (P d)=-4.684+0.815 M w-1.36 \log R \quad(5)$ From Eq. (5), the authors could find the estimation of hypocenter distances.

Quick estimation of epicenter determination by using three components of broadband seismogram polarity, incident angel and hypocenter distances. Correlation among $P d, R$ and $M$ is shown in Fig. 11. 
The important think at EEW parameter to determine hypocenter distance. Eq. (5) showed relationship $P d$, $M w$ and $R$. Amplitude displacement at $3 \mathrm{~s}$ P-wave arrival will lost this energy, function of hypocenter distance. Response amplitude suppress 10 times in Bandung station (LEM) is about $100 \mathrm{~km}$ from CISI station. From this formula if people knew hypocentral distance $R$, polarization of $\mathrm{P}$-wave in three components BB seismograph and people could determine estimation of epicenter. To know the effect of earthquake to the damaging structure, usually declare by parameter of peak ground displacement.

\subsection{The Mathematical Model Pd and PGA}

Correlation between amplitude displacement $(P d)$ and $P G A$ calculated from linier fit of double logarithmic data analysis. $P d$ determined from maximum amplitude of displacement during $3 \mathrm{~s}$ of P-wave arrival time, similar analysis for $P d$ and $P G A$. $P G A$ calculated from maximum peak ground acceleration of simulation seismogram acceleration and processed in $\%$ of g. Eq. (6) is the result of linier fit double logarithmic of $P d$ and $P G A$ :

$$
\log P G A=1.117 \log P d+0.728(R=0.91)
$$

Correlation ratio $P d$ and $P G A$ using 68 earthquakes data show in Fig. 12.

According to analysis for engineering parameter of $P G A$, Eq. (6) shows the correlation of $P d(\mathrm{~cm})$ and $P G A$ (\%, g). A threshold of $P G A>25 \% \mathrm{~g}$ associated with $P d>0.5 \mathrm{~cm}$ (Table 2). Value of $P G V$ and $P G A$ in the area of west Java could be determined by Eq. (5) to find $P d$ and after that from Eqs. (5) and (6) to find $P G A$. BMKG already have DVB (digital video broadcast) for operational. It is possible to joint information so far for design EEW.

\section{Conclusions}

Lead time of strong ground shaking of S-wave to reach Bandung and Jakarta is around $50 \mathrm{~s}$ and $118 \mathrm{~s}$.

Threshold warning for potentially damaging in West Java area can be predicted from the characteristics of the dominant period $T d>1.2 \mathrm{~s}$ and magnitude estimation $M T d>6.0$.

Earthquake damage in structure is expressed by estimation of $P d>0.5 \mathrm{~cm}$ and $P G A>25 \% \mathrm{~g}$.

CTBT station (LEM), Lembang, Bandung, west of Java, Indonesia have a good performance data with signal to noise ratio $>1,000$.

\section{Acknowledgments}

The authors give thanks to CTBTO S \& T 2011 Conference, Director of BMKG for Ph.D. program, $\mathrm{P}$ lecturers and colleagues in ITB for technical assistance.

\section{References}

[1] H. Negishi, S. Yamamoto, Earthquake early warning system at a local goverment and a private company in Japan, in: 1st European Conference on Earthquake Engineering and Seismology, Geneva, Switzerland, Dec. 3-4, 2006, p. 741.

[2] Y.M. Wu, H. Kanamori, Development of EEW Using Real Time Strong Motion, Management Development Institute, 2008.

[3] Z. Chen, R. Stewart, A Multi-Window Algorithm for Real Time Automatic Detection and Picking of P Phase of Microseismic Events, CREWES research report, Vol. 18, 2006.

[4] T. Akazawa, A technique for automatic detection of onset time of $\mathrm{P}$ and S-phase in strong motion records, in: 13th Word Conference on Earthquake Engineering, Canada, 2004.

[5] R.M. Anya, W. Mao, D. Gubbins, Polarization filtering for automatic picking of seismic data and improved converted phase detection, Geophys Journal International 147 (2001) 227-237.

[6] J.J.G. Merino, J.R. Herran, S. Parolai, Seismic phase picking using a kurtosis based criterion in the stationary wavelet domain, in: IEEE Transactions on Geoscience and Remote Sensing, USA, 2007, pp. 3815-3826.

[7] S. Gentili, A. Michelini, Automatic picking of P and S wave phase using neural tree, Journal of Seismology 10 (2006) 39-63.

[8] Y.M. Wu, H. Kanamori, Experiment on an onsite earthquake early warning method for the Taiwan early warning system, Bulletin of the Seismological Society of America 95 (1) (2005) 347-353. 